\title{
DE REGNO O EL TRASTORNO TOMISTA DE LA UNIVERSALIDAD POLÍTICA
}

\author{
Rafael Esteban Gutiérrez Lopera* \\ doi: 10.11144/Javeriana.uph38-76.rtup
}

\section{RESUMEN}

Este estudio versa sobre las alteraciones de ciertas ideas de la filosofía política aristotélica con ocasión de su cruce con la exégesis agustiniana de la doctrina cristiana, promovido por Tomás de Aquino en su Tratado sobre el reino (De regno). Lo que sigue es una revisión del lugar que le corresponde en la obra al carácter universal de la política, que en la filosofía de Aristóteles yacía ligado al naturalismo político y que en la recepción tomista parece proyectarse hacia un registro sobrenatural y divino. Para evaluar esta conjetura nos remitimos a las causas y fines atribuidos por Tomás al dominio del hombre sobre el hombre, intentando rastrear el lugar que ocupa la virtud política en el planteamiento. La hipótesis por sustentar es que la caracterización que hace Tomás del modelo político del reino implica una bifurcación en el fin hacia el que la comunidad política tiende, todo lo cual propiciaría la desuniverzalización de la política misma.

Palabras clave: Tomás de Aquino; De regno; Aristóteles; universalidad; virtud política

\footnotetext{
Universidad de Buenos Aires, Argentina.

Correo electrónico: esteban.gutierrez@usantotomas.edu.co

Para citar este artículo: Gutiérrez Lopera, R. E. (2019). De regno o el trastorno tomista de la universalidad política. Universitas Philosophica, 38(76), 113-137. ISSN 0120-5323, ISSN en línea 2346-2426. doi: 10.11144/Javeriana.uph38-76.rtup
} 


\title{
DE REGNO OR THE THOMISTIC DISORDER OF POLITICAL UNIVERSALITY
}

\begin{abstract}
This study deals with the transformations of a number of topics of Aristotelian political philosophy provoked by their crossing with the Augustinian interpretation of Christian doctrine, promoted by Thomas Aquinas in his Treatise on the Kingdom (De regno). The following is a review of the place of the universality of politics in Aquinas's text, which in Aristotle's philosophy was linked to political naturalism and that in Thomist reception seems to tend towards a supernatural and divine scenario. In order to evaluate this conjecture we will refer to the causes and ends attributed by Thomas to the dominion of man over man, trying to recognize the place occupied by political virtue in this approach. The proposed hypothesis is that Thomas's characterization of the political model of the kingdom implies a bifurcation in the end to which the political community aims, all of which would propitiate the de-universalization of politics itself.

Keywords: Thomas Aquinas; De regno; Aristotle; universality; political virtue
\end{abstract}




\section{Introducción: el legado agustiniano}

CONVIENE INICIAR RESEÑANDO ciertos rasgos distintivos del pensamiento de San Agustín de Hipona, pues su obra conduce toda una tradición teológica de pensamiento que deviene antecedente obligado de los temas en torno a los cuales reflexionará Santo Tomás de Aquino en el tratado que es objeto de este estudio.

A propósito del integral deterioro padecido por Roma durante el siglo $\mathrm{v}$, Agustín se dispone a polemizar contra paganos, gentiles, extranjeros y otros ajenos al cristianismo, entre quienes habría cundido la opinión general de que el gesto desencadenador del declive habría sido la adopción del culto cristiano por parte de la cabeza imperial de occidente mediante el Edicto de Tesalónica en 380 d. C. En este contexto, el obispo de Hipona redacta entre 412 y 426 d. C. $L a$ Ciudad de Dios (2010), donde presenta alegatos de la mayor envergadura acerca de la genuina identidad del ordenamiento político temporal o terrenal. Si bien las disquisiciones sobre cuestiones políticas no son el eje neurálgico en el corpus agustiniano, ellas impactan, como veremos, en la obra de Tomás de forma más profunda de lo que suele apreciarse. En lo que nos concierne, nuestro teólogo argumenta a favor de dos hipótesis: de un lado, que las relaciones de dominio entre el género humano no hacen parte de la naturaleza con la que Dios insufló al hombre en la creación, sino que tal rasgo germina como la consecuencia estigmatizante y artificiosa del pecado original. Por otro lado, que no se deduce de las instituciones establecidas en esta vida terrena nada que alcance la perfección, dignidad y virtud de las cuales gozaba la especie en el estado supralapsario de inocencia, es decir, en el estado anterior a la caída. Aquí resaltamos que, en la defensa de ambas proposiciones, Agustín configura una suerte de inversión de los términos en los que Aristóteles habría desarrollado su concepción naturalista de la política -a cuyos aspectos centrales atenderemos en breve-, oponiéndose a Aristóteles solo indirecta y desprevenidamente, pues la Politica del Estagirita era todavía desconocida por la cultura romana durante el periodo de producción de Agustín.

$\mathrm{Al}$ crear al hombre, aduce Agustín, Dios "no lo ha querido hacer dueño más que de los seres irracionales. No ha querido que el hombre dominara al hombre, sino el hombre a la bestia”, o lo que es igual, le ha dotado de una suficiencia en razón de la cual se despeja toda necesidad de que unos se alcen por encima de los otros estableciendo relaciones de obediencia (civ. Dei XIX, 15). "Los primeros 
justos fueron puestos más bien como pastores de rebaños que como regidores de hombres", de suerte que, en contraste con las criaturas irracionales, en la condición humana se verifica cierta simetría que consuma la virtud de su naturaleza creada y que suscita la pregunta sobre el origen de la asidua disposición histórica de los hombres a levantar instituciones y someterse a ellas (civ. Dei XIX, 15). La respuesta de Agustín a esta cuestión es célebre por su contundencia: la situación de esclavitud que se sigue del dominio entre los hombres es una imposición que recae sobre la ontología pecadora, esto es, "ha sido, pues, el pecado quien ha acarreado este concepto, no la naturaleza. [...] La causa primera de la esclavitud es, pues, el pecado, que hace someterse un hombre a otro hombre como un vínculo de condición social" (civ. Dei xIX, 15). En consecuencia, Agustín entiende que el pecado original, mediante el cual la naturaleza humana adquirió su defectuoso estatus poslapsario, condena a la especie a ser la frecuente espectadora del desmoronamiento de cada estructura, artificio, institución o ciudad que sea fundada con la pretensión de recrear la virtud, perfección y suficiencia que ostentaba el hombre en su estado original. Apelando a las ideas más habituales de la tradición neoplatónica, Agustín arguye que "estos filósofos [...], con una desvariada pretensión, han querido ser felices en esta tierra, y alcanzar por sí mismos la felicidad" (civ. Dei xIx, 4). No obstante, replica, "se burla de ellos la verdad", puesto que todo reino sublunar, como la decadente Roma a la que comunes y eruditos consideraron por igual inexpugnable, virtuosa y eterna, paga el precio de una materia antropológica agrietada por el pecado (civ. Dei xIX, 4). Desde luego, la consecución de felicidad, virtud, suficiencia y universalidad queda reservada para la única ciudad a la que puede considerarse sensatamente perfecta, a saber: la Civitas Dei o Ciudad de Dios.

Varios siglos después, entre 1265 y 1267, mientras Tomás de Aquino se encontraba comentando la recientemente redescubierta obra aristotélica, y poco antes de iniciar su más célebre trabajo (Summa Theologiae), el Doctor Angélico emprendió la redacción paralela del De regno ${ }^{1}$, un ensayo inacabado donde se

1 Antonio Tursi, autor de la traducción de la Editorial Losada, menciona que la autoría de Tomás sobre el tratado es constatada por monjes cercanos a él en varios documentos que enlistan sus obras. Las mismas fuentes advierten que el autor dejó inconclusa la escritura, y "su discípulo y biógrafo, Tolomeo de Lucca, la completó con una segunda parte” (Tursi, 2003, p. 51). No obstante, 
proponía dilucidar el verdadero origen de un reino, por un lado, y el deber al que estaría sujeta la labor de su rey, por el otro. "El De regno es un escrito de circunstancia” (Tursi, 2003) esto es, una pieza inscrita en la discusión teológicopolítica del Medioevo occidental sobre el origen de las relaciones de dominio y el trato, o disposición jerárquica, entre el poder espiritual del sacerdocio y el poder temporal de príncipes, reyes y emperadores (p. 52$)^{2}$. En medio de este debate, en el que la doctrina agustiniana ostentaba un protagonismo pujante, Tomás sería reconocido en su esfuerzo por hacer concordar tan armónicamente como fuere posible los pilares de la tradición cristiana con la estructura teorética de Aristóteles; de ahí que sus fuentes medulares sean, según anota en las primeras páginas del texto, las Sagradas Escrituras, la "doctrina de los filósofos", ejemplos históricos elogiables y el auxilio divino de Dios $^{3}$.

Suele anteponerse la idea de que, en tanto deudor de las enseñanzas aristotélicas, Tomás guardaría diferencias irreconciliables con Agustín y una cercanía plena con Aristóteles, en su forma de entender el dominio político entre los hombres. "Tomás fue el único escritor [de su época] que no solo comprendió perfectamente al filósofo [Aristóteles], sino que, además, y precisamente por ello, comprendió las potencialidades que encerraba su doctrina”, según afirma un erudito en la materia como Walter Ullman (1985, p. 245), cuyas palabras,

el punto preciso en el que finaliza la redacción de Tomás e inicia la de Tolomeo sigue siendo objeto de debate.

2 El contexto de redacción, antes, durante y después del siglo XIII, estaba atravesado por la tensión permanente entre dos potencias: monárquicas, de un lado, e hipocráticas, del otro, las cuales litigaban mutuamente para desplazar a la otra y posicionarse en el centro de proyección de la obediencia de las gentes. El profesor Francisco Bertelloni (2005) señala que, "quizá sin intentarlo, Tomás estaba planteando uno de los problemas más relevantes de toda la teoría política: el problema de la existencia simultánea de dos poderes coactivos sobre un mismo súbdito" (pp. 18-19).

3 Introducir a Aristóteles en un debate donde la cosmología cristiana ostentaba una autoridad rampante era una labor vista entonces con la misma incredulidad con la que se la puede ver ahora. Tomás, reconocen autorizadas fuentes como Ullman, fue capaz de efectuar tal empresa. No obstante, el estudioso austriaco insinúa que la tarea se llevó a cabo a costa de sacrificar aspectos centrales del aristotelismo al informar que "Tomás se propuso crear una síntesis, delicada y en cierto sentido frágil, es cierto, de elementos irreconciliables y dispares -cristianos, estoicos, neoplatónicos, aristotélicos-, pero que privaba al aristotelismo de ingredientes que, desde el punto de vista teocrático, podían correctamente considerarse dañinos" (Ullmann, 1985, p. 245). 
aunque deben leerse con precaución, pueden tomarse como ejemplo del entusiasmo con el que se evalúa la obra de Tomás en el sentido indicado. Mediante un seguimiento ordenado de los temas, argumentos y tesis contenidas en De regno, intentaremos objetar este presupuesto y sustentar una posición diferente: al no haberse desembarazado de la tesis agustiniana de una antropología poslapsaria que arrebata a la vida terrena del hombre toda posibilidad de virtud, perfección y universalidad, Tomás, en conflicto con Aristóteles, habría impregnado con esta idea el núcleo de su concepción de la política.

2. ¿Es natural la política?: naturaleza y fin de la especie

Denominamos “NATURAlismo político aristotélico" a la proposición filosófica de acuerdo con la cual la especie humana está naturalmente predispuesta hacia la vida en sociedad y la conformación de comunidades políticas. En el segundo capítulo del libro primero de la Política aparece célebremente expresado el juicio de Aristóteles: "la ciudad-Estado se halla entre las cosas que existen por naturaleza y el ser humano es por naturaleza un animal político" (Politica I, 2, 1253a). Se desprende de este principio una estratificación jerárquica entre los miembros de la especie, los cuales o bien nacen libres y con facultades de mando, o bien nacen no-libres e innatamente motivados para la obediencia. Fiel al espíritu filosófico de su época, y a las enseñanzas de Platón, Aristóteles considera que una parte de este naturalismo político consiste en la dinámica organicista donde "aquel que tiene la capacidad para proyectar con la razón domina por naturaleza y es amo por naturaleza, y aquel que tiene la capacidad de realizar tareas con el cuerpo resulta dominado y es esclavo por naturaleza" (Política I, 2, 1252a). Característico del pensamiento aristotélico es la formulación de enunciados que no se reducen a la experiencia histórica específica, no por ignorar arbitrariamente tal especificidad, sino por pretender contenerla en un saber filosófico y científico que se remite a la naturaleza universal de aquello por lo cual se pregunta, pues "siempre hay alguna naturaleza, sea una o más de una, a partir de la cual se genera lo demás, conservándose aquella" (Metafísica I, 3, 983b). Si suponemos que la tesis del naturalismo político pretende satisfacer este parámetro, repararemos en que la politicidad es, para Aristóteles, una dimensión universal respecto de la naturaleza humana, "por eso 
toda ciudad-Estado existe por naturaleza, si también por naturaleza existen las primeras comunidades: puesto que la ciudad-Estado es el fin de aquellas, y la naturaleza es fin" (Politica I, 2, 1252b).

Esta vinculación, con la que se concluye la cita, entre el principio de algo y su fin es otro rasgo que conviene destacar, pues allí reposa el sesgo teleológico tan típico del aristotelismo, en razón del cual, cuando se han seguido adecuada y racionalmente los designios de la naturaleza, se emparentan las virtudes de origen con las virtudes del fin. En efecto, para Aristóteles el fin propio de una especie política por naturaleza, y que "tiene por naturaleza armas para la prudencia y la virtud”, es necesariamente un fin virtuoso, lo cual, sin embargo, no implica que este o aquel hombre en particular, desviándose de sus disposiciones naturales, soslaye siempre el riesgo de tornarse "el animal más impío y salvaje" (Política I, 2, 1253a). En lo que a la disposición teleológica concierne:

Lo importante es que toda institución social reproduzca el organicismo universal. [...] La polis no es una mera suma o agregado de partes, sino un organismo; y la finalidad que condiciona teleológicamente todos los momentos de la comunidad tradicional es la autarquía, perfección ontológica y ética a la vez (Dotti, 1994, p. 54).

La universalidad de esta virtud atestiguada en la comunidad política hace que ella sea tan apreciable en los libres como en los no-libres (mujeres, niños, esclavos, extranjeros, trabajadores manuales), pues lo que conviene a quien ordena es idéntico de lo que conviene a quien obedece, en razón de que lo que es bueno para cada uno es la identificación de su naturaleza con su respectivo fin. Así, Aristóteles afirma que le "resultaría sorprendente que uno participara de la excelencia y el otro no", pues si el dominado y quien domina adecúan su actuación en la polis a lo que su naturaleza los orienta, entonces, "resulta evidente que ambos participan necesariamente de la virtud” (Política I, 13, 1259b-1260a). En palabras de Jürgen Habermas (1987), "Aristóteles está convencido de que una polis [...] debe apoyarse en la virtud de sus ciudadanos" (p. 54), esto es, de un lado, la polis deviene el punto culmen del despliegue de los medios que le son naturales a la condición humana, y, del otro, su "causa final" es la consecución de una vida perfecta y autosuficiente, todo lo cual hace de este orden político la constatación del encuentro entre naturaleza, política y universalidad. 
Las discrepancias y contrastes entre los alegatos de Aristóteles en la Política y las tesis de Agustín en De civitate Dei saltan a la vista. Retratemos brevemente los contrapuntos que consideramos más significativos para la construcción de nuestro argumento: Aristóteles tiene como punto de partida una condición humana política por naturaleza, cuyos miembros, aunque vulnerables ante los atributos y destrezas de otras especies, se hallan ontológicamente predispuestos a corresponder a su lugar en una jerarquía macrocósmica. Así, en el seguimiento del derrotero teleológico que tiende el puente entre la naturaleza de algo y su fin, el género humano está en condiciones de hacerse con una vida virtuosa en el marco de la comunidad política. Por su parte, Agustín, que en esto oscila entre los registros previo y posterior a la caída del hombre, presupone una naturaleza autosuficiente para la antropología creada por Dios e insuficiente para su versión herida por el pecado adánico; en el primer caso, la autarquía supralapsaria, simétrica en su perfección, haría innecesaria toda organización política, pues todos los fines posibles estarían ya consumados; en el segundo, la radical finitud poslapsaria hace de la política un hecho irreparablemente defectuoso, cortesía de una materia que no ha sido diseñada para la vida en comunidad. De tal modo, mientras Aristóteles entiende que la virtud se realiza en un orden político terrenal favorecido por la naturaleza humana, como es el caso de la ciudad-Estado, Agustín desdice objeta cualquier identificación posible entre la vida terrena de una naturaleza pecaminosa y la virtud, pues un fin semejante es exclusivo del reino celestial.

Explicados los rudimentos de las fuentes de la argumentación de Tomás de Aquino, adentrémonos ahora en los avatares de su texto. Lo primero a destacar es que, en un gesto de acercamiento al modelo aristotélico, el tratado de Tomás se propone disertar en favor de un origen natural de las relaciones de dominio, sin redundar, como acontece con Agustín, en una comprensión peyorativa de la política. En este sentido, ya desde las primeras líneas del De regno se plantean dos apelaciones que serán constantes a lo largo de la trama conceptual: por un lado, en expresa suscripción a la tesis central del naturalismo aristotélico, la invocación de una naturaleza humana social y política. Por el otro, el reiterativo anuncio de un fin encumbrado hacia el cual estaría orientada toda vida y acción humana, cuyo contenido, sin embargo, no se nos revela en lo inmediato y quedará como una incógnita en suspenso hasta bien avanzada la discusión. Tomás 
se compromete así con explicar de qué manera la política sería capaz de producir las condiciones de su propia fundamentación, empleando para ello los medios ordinarios de los que la naturaleza humana dispone, sorteando su reducción a un accidente pecaminoso, y sin dejar de concordar con el canon bíblico. Para tal propósito, el autor se pregunta figuradamente si le convendría al hombre vivir aisladamente, suponiendo que nada en su estructura natural le exhortase a entablar vínculos comunitarios. Para Tomás, esta posibilidad trae consigo una dificultad relacionada con la condición precaria de la especie, aspecto en el que Aristóteles y Agustín no riñen drásticamente. En su constitutiva falencia, los humanos no se distinguen mucho de otros animales, aunque a diferencia de estos, que cuentan con pieles, colmillos, garras, cuernos y otros medios similares para subsanar sus necesidades más primordiales, a la humanidad le fue suministrada la razón, por medio de la cual, en correlación con el trabajo de sus manos, está en condición de obtener cierta suficiencia. Sin embargo, explica Tomás, la luz de la razón de un solo hombre le es insuficiente para reproducir por sí mismo su propia vida, de suerte que, "corresponde al hombre que sea un animal social y político, que vive en una multitud más aún que todos los otros animales; lo que, por cierto, su necesidad natural revela" (Tomás de Aquino, 2003, pp. 63-64). $\mathrm{Al}$ igual que en la fórmula aristotélica, el texto nos presenta un ser privado de autosuficiencia y carente de los medios necesarios para reproducir aisladamente su existencia vital, una circunstancia que conduce a la conclusión de que la supervivencia solo es posible mediante la asociación y por efecto de la articulación coordinada de la razón de muchos.

De esta manera, es posible afirmar que el autor ofrece un sustento satisfactorio a la idea según la cual la sociabilidad es un rasgo inherente a la naturaleza humana, apoyándose sobre las limitaciones deducidas de la necesidad innata. No obstante, en el rigor de la perspectiva aristotélica, queda aún pendiente un argumento por el cual se explique la naturaleza no ya meramente social de la antropología humana, sino su naturaleza específicamente política. Para Aristóteles, si bien es cierto que el gesto asociativo permite subsanar las más elementales necesidades para el sostenimiento fisiológico de la especie, esta intención se proyecta, todavía, en una instancia prepolítica, representada bien en la casa, bien en la aldea, a las que corresponde la satisfacción de las necesidades más y menos cotidianas. A "la comunidad perfecta conformada", o ciudad-Estado, le es propio 
un fin diferente a la generación de la mera vida, esto es, "surgió para la vida pero existe para la vida buena", lo que la hace la comunidad política propiamente dicha (Politica I, 2, 1252b) ${ }^{4}$. En ese sentido, por lo pronto, Tomás condiciona su invocación del naturalismo social y político exclusivamente al atendimiento de una antropología de la precariedad, de la cual, suponiendo que continúa circunscrito al derrotero de la Política, debería extraer a la politicidad en el corto plazo.

\section{El dirigente como condición de la institución política}

Tomás AdUCE QUE LA IDEA CONTRAFÁCtica de un ser humano al que no le correspondiese vivir en sociedad derivaría en un panorama en el que cada quien cumpliría la función de ser rey de sí mismo, esto es, cada hombre se vería exhortado a perseguir su fin encaminándose hacia él exclusivamente por la vía que su propia consciencia le hiciere ver como la más conveniente. No obstante, al igual que sucede en el planteamiento aristotélico, de que un fin sea natural no se sigue que las maneras de avanzar hacia él se reduzcan a ser una y la misma, sino que tal proceso tiende a diversificarse y, la mayoría de veces, a desviarse. En vista de ello, se hace necesario recurrir a una medida rectora que ilumine y enseñe el camino a seguir. Es así como el autor empieza a tender un puente que va desde el impulso natural de asociación hacia la institución del más óptimo de los regímenes: el reino o la monarquía. El Doctor Angélico se propone justificar la emergencia y predilección de un único dirigente, llamado rey, al que le es asignada la tarea de gobernar sobre la colectividad de un reino y ordenar sus recursos en vista a garantizar su correcto avance hacia el fin previsto.

Ahora, si bien es cierto que al hombre le es natural desarrollarse estableciendo vínculos asociativos, dado que las formas de encaminarse hacia el fin son heterogéneas, al interior de las comunidades instituidas se gesta la coexistencia de diferentes versiones sobre lo que es más conveniente para el conjunto, lo cual lleva a que la multitud adopte posturas partidarias sobre el sentido sustancial de su propio bien, haciendo, a su vez, que la comunidad se torne, a través del desacuerdo,

4 Para el Estagirita, la consideración de los fines relativos a cada comunidad es harto significativa, pues en la pregunta sobre los elementos sustanciales, y no meramente formales, que hacen una comunidad, va implicado el criterio que permite distinguir un oikos grande de una polis chica. 
"una carga para sí misma" (Tomás de Aquino, 2003, p. 68). Tomando el disenso como base del problema, el maestro de la Universidad de París explica que la multitud asociada requiere de un principio que rija de manera unitaria sobre el bien común, y en ausencia de lo cual solo cabría esperar su segregación, pues "donde no hay gobernador, el pueblo se disipará" (Proverbios, 11:14), sentencia el autor a través del monarca bíblico Salomón (Tomás de Aquino, 2003, p. 65). Queda así despejado el camino para aclarar que el abanderado principal del interés común de la multitud, a quien atañe garantizar que la "unidad de la paz" se conserve, no es otro que el rey. En síntesis, considerando que un cuerpo colectivo pluralista deviene obstáculo para sus propios objetivos, Tomás sostiene que la manera adecuada de aproximar a las gentes hacia el fin que les es propio es agrupándolas bajo un mismo régimen con arreglo a aquello que es de por sí unidad en lugar de pluralidad, a saber: el rey, en quien recae tanto la potestad como el deber tanto de reinar sobre la comunidad política ya fundada como de fundar la ciudad o el reino que unifique la paz de su pueblo. Aquí, nuestro filósofo parecería sugerir que la naturaleza social de la que nos informó preliminarmente no basta por sí misma para mantener a la multitud efectivamente congregada en torno al bien común, sino que para tal efecto hace falta complementar la operación con la aparición de un dirigente. El rey parece, entonces, devenir condición de posibilidad para que la comunidad adquiera su estatus político bajo el amparo del reino, que es, según entiende Tomás, el más justo entre los regímenes políticos posibles.

Frente a esta cuestión, resulta sugestivo considerar cómo se explica en De regno el deber de los reyes. Por un lado, Tomás intenta deducir las obligaciones a las que estaría sujeta la cabeza de un gobierno terrenal acudiendo como referente analógico nada menos que al "régimen universal" que agrupa toda cosa, criatura, cuerpo y fuerza bajo la providencia divina de un mismo Dios que las rige. Mediante un razonamiento que data en la filosofía occidental desde la Física de Aristóteles, según el cual la naturaleza es imitada por el arte humano, Tomás estriba en las complejidades del régimen de la naturaleza para deducir de allí el deber del rey, "mas se encuentra en la naturaleza un régimen universal y otro particular” (Tomás de Aquino, 2003, p. 107). A partir de este gesto, que se presenta como analogía, pero en realidad es distinción, el gobierno temporal del rey es concebido ya desde la filosofía tomista como una particularidad derivada a imagen y semejanza de la universalidad mediante la cual Dios ha hecho el mundo 
y gobierna sobre él. Por otra parte, es justamente aquí donde el teólogo realiza un movimiento que suscita un cisma en la finalidad hacia la cual está proyecta la pertenencia civil de los súbditos. Para Tomás (2003), gobernar no es otra cosa que "llevar convenientemente lo que es gobernado a su debido fin" (p. 112), y su forma de ilustrar los deberes que de tal labor se siguen es mediante una metáfora náutica, frecuente tanto en la tradición clásica como en la escolástica:

se dice que la nave es gobernada, mientras es llevada ilesa por la habilidad del marinero hasta el puerto por una ruta directa. Entonces, si algo se ordena a un fin exterior a sí mismo, como la nave al puerto, al deber del gobernador pertenecerá no solo conservar la cosa ilesa en sí, sino también llevarla después hasta el fin. [...] sin embargo respecto de aquello que está ordenado a un fin extrínseco, su cuidado se da de múltiples maneras por diversas formas. Pues acaso uno será quien procure que la cosa se conserve en su ser, y otro que alcance su última perfección, como resultado manifiesto del mando (gubernatio) en la misma nave, de donde se toma el nombre de gobierno (Tomás de Aquino, 2003, pp. 112-113).

Toda la trama argumental de la obra a la que atendemos presupone el discernimiento entre aquello que está ordenado hacia un fin extrínseco al reino y aquello que lo está hacia un fin intrínseco a él (Tomás de Aquino, 2003, p. 112)5. A partir de esta distinción, recién consagrada en el tercer capítulo del libro segundo, la propuesta tomista se revela novedosa e irregular respecto de sus fuentes. Para el Doctor Angélico, el llevar al reino hacia buen puerto pertenece al género de procesos en los que van implicados dos o más propósitos diferentes y, en consecuencia, dos o más deberes distintos. Para el caso concreto del reino, un fin es intrínseco y consiste en conservarlo ileso y a salvo, mientras otro es extrínseco e implica guiarlo hacia su enigmático y todavía inadvertido fin último.

5 Otro referente para el estudio de las ideas políticas en occidente, como Leo Strauss (2000), detecta que la partición entre la proyección intrínseca y extrínseca redunda en que "el fin natural del hombre es insuficiente, o que apunta más allá de sí mismo o, para ser más exactos, que el fin del hombre no puede consistir en la investigación filosófica, por no mencionar la actividad política" (p. 219). Ahora, Tomás (2003) afirma en un par de ocasiones a lo largo del texto que "conviene que sea el mismo el juicio respecto del fin de toda la multitud y el de un solo hombre” (p. 113), de lo cual, empleando los términos sugeridos por Strauss, nos sería posible intuir que el fin del reino, al apuntar más allá de sí mismo, delata su insuficiencia. 
En los términos del texto, el primer fin es terrenal y mundano, mientras que el segundo está revestido de la gracia divina que de su asociación con Dios deriva. Lo que se podría conjeturar, sin embargo, es que al rey, en su deber de gobierno, le compete asumir ambas funciones, tanto la de procurar la supervivencia del reino como la de garantizar que alcance su fin último. Mas Tomás (2003) niega esta posibilidad arguyendo que "un régimen tal pertenece a aquel rey que no solo es hombre, sino también Dios, a saber a Jesucristo el Señor” (p. 114), con lo cual, una suposición como esta incurriría en el error de ignorar la desproporción entre la universalidad del gobierno de Dios y la particularidad de gobierno del rey. El único rey al cual le compete dominio temporal y divino simultáneamente es Jesucristo, lo cual relega la tarea de gobierno a satisfacer uno solo de los dos registros. Hasta aquí, el deber del rey no parece ser otra cosa que garantizar la supervivencia de la colectividad gobernada - un fin que no alcanza todavía la dignidad política según estándares aristotélicos, y permanece anclado a aquello que dimos por llamar "antropología de la precariedad"-, mientras a otro -ya veremos quién- le sería encomendada la orientación de la nave hacia su fin extrínseco, que es el verdadero fin último.

\section{El lugar de la virtud: el fin del hombre no es político}

TOMÁS ESGRIME DE DISTINTAS MANERAS y en diferentes momentos buena parte de los argumentos aprendidos de su lectura de la Política. A pesar de ello, un par de elementos medulares para la concepción aristotélica del tema aún no han tenido en De regno el grado de participación del que gozan en la obra de Aristóteles. Entre las ausencias más significativas para nuestros propósitos argumentales figura la dimensión política de la virtud o, más claramente, la virtud política que se realiza en el escenario de la comunidad cívica. Algo a propósito de la cuestión de la virtud se desarrolla al tematizar el "premio" que habría de recibir el rey por desempeñar un gobierno justo y en favor del bien común. Parafraseando al teólogo italiano, no es conveniente considerar que un rey pueda someterse al rigor de los compromisos y trabajos que su cargo supone, si a cambio solo recibe el honor y la gloria que provienen de una fuente sencillamente humana. Para atender a la razón de esto se nos remite a una simpática metáfora que alude a la fragilidad de una flor de heno para representar la cualidad inconsistente, efímera 
y caprichosa de la glorificación que es producto de los hombres. Acudiendo al propio Agustín, Tomás sentencia que "la gloria que los hombres desean no es otra cosa [...] que un juicio de unos hombres que opinan bien sobre otros hombres" (civ. Dei v, 12), pero nada es, de acuerdo a esta visión, más mutable y engañoso que la palabra de los hombres, e igualmente inestable lo será aquello que de ella dependa para convalidarse (Tomás de Aquino, 2003, p. 85). Se entiende, pues, que cualquier tentativa de virtud mundana, cuyo sustento repose únicamente en la opinión del hombre, resultará indigna como medida de retribución a la labor del rey. De esta manera se advierte la reintroducción de un criterio valorativo de estirpe agustiniana, en función del cual nada que tenga su origen en la naturaleza humana puede alcanzar un grado estimable de perfección o universalidad, dada la inconsistencia e incompletud a la que se halla condicionada. Intuimos con Bertelloni (2005), que "esa naturaleza y ese aristotelismo [que inauguraban el argumento de Tomás] empiezan a delatar un vaciamiento de su contenido original y su reemplazo por un contenido diferente" (p. 24), pues con este gesto, Tomás no solamente contribuye al proceso de devaluación de la virtud humana, por considerarla una construcción que paga el precio de una ontología precaria, sino que también estimula un proceso de embargo de las potencialidades atribuidas por Aristóteles a la política ${ }^{6}$. Con arreglo a este razonamiento, Tomás aborda la cuestión del premio del rey formulando cuestionamientos en los que parece venir implícita su respuesta:

¿qué honor mundano y caduco puede ser igual a ese honor de ser el hombre conciudadano de los santos y familiar de Dios, de que contado entre los hijos de Dios, alcance con Cristo la herencia del reino celestial? [...] ¿qué gloria de alabanza humana se puede comparar a esta gloria, que no la refiere la lengua falaz de los aduladores ni la opinión errada de los hombres, sino que surge del testimonio de la conciencia interior y es confirmada por el testimonio de

6 El giro valorativo que imprime el sesgo agustiniano de Tomás hace que se anteponga constantemente una situación irrenunciable de radical caducidad, finitud e insuficiencia a todo aquello cuya causa sea la naturaleza humana, la cual, como cabría esperar, "pierde su carácter de entelequia y perfección ético-racional del hombre y deviene motor del hombre hacia la satisfacción de las necesidades de su vida" (Bertelloni, 2005, p. 25). 
Dios, quien a los que le confiesen promete que los confesará en la gloria del Padre, frente a los ángeles de Dios? (Tomás de Aquino, 2003, p. 90).

Desde luego, si la gloria humana es tan inadecuada para abastecer con suficiencia el merecimiento del rey, por su carácter deleznable y volátil, y considerando, en palabras de Tursi (2003), que "el rey no puede ser, en una sociedad cristiana, sino cristiano", entonces, lo verdaderamente conveniente es que la recompensa que al rey corresponde sea dada por una instancia superior al rey mismo (p. 53). En su encargo de gobernar un reino particular, el rey funge como ministro del reinado universal de Dios, de manera que, suponiendo que han gobernado con justicia, y "no por el ardor de una gloria vacía, sino por caridad de la felicidad eterna” - alega Tomás en palabras de Agustín-, es de Dios de quien los reyes reciben el beneficio esperado por sus servicios (Tomás de Aquino, 2003, p. 89). Tal es "un grado sublime y eminente de felicidad celestial", de la cual gozan, por lo pronto, en esperanza, pues la universalidad no tiene lugar en el plano terrenal sino como expresión de fe, y posteriormente, de hecho, con el advenimiento de la trascendencia divina (p. 91).

Dicho esto, para el Doctor de la Humanidad es sumamente difícil hacer un adecuado tratamiento del premio del rey sin acabar revelando también el fin último del cual nos advirtió inicialmente, y hacia cuya consecución se habría de orientar cada acto de la vida terrena. Deducida por la facultad racional humana, "la felicidad es la perfección final del hombre y su bien acabado al cual todos desean alcanzar" (Tomás de Aquino, 2003, p. 89). No obstante la enunciación de lo que parece ser el fin hacia el que la naturaleza humana tiende, Tomás incurre nuevamente en un gesto que se torna familiar en su argumentación, de acuerdo con el cual corresponde devaluar toda posibilidad de recrear algo tan pleno como autosustentable en las dramáticas condiciones temporales a las que está sujeta la condición humana. Este bien perfecto llamado felicidad, que es de una dignidad tal que nadie puede no desear para sí mismo, y que una vez obtenido no quedaría nada más que pudiese desearse, no es la excepción a la regla. "Nada hay de lo creado que haga feliz al hombre ni pueda entregársele al rey como premio" (2003, p. 89), considerado lo cual el fin último de la especie no encuentra las aptitudes para su realización en ninguno de los medios naturales que le son dados al ser humano, incluida, desde luego, la vida en la comunidad política de la que su politicidad innata es tutora. El distanciamiento de Tomás respecto de Aristóteles se torna así en oposición. 
Resta, entonces, preguntarse cuál es el lugar genuino al que corresponde la consecución del bien universal. En respuesta a esta cuestión, Tomás emplea el siguiente silogismo:

El deseo de cada cosa tiende a su principio, por el cual su ser es causado; mas la causa de la mente humana no es otra cosa que Dios quien la hace a imagen suya; entonces, solo Dios es quien puede aquietar el deseo del hombre, hacer feliz al hombre y ser el premio conveniente para el rey. Más aún, la mente humana es cognoscitiva del bien universal gracias a su intelecto y desiderativa del cual gracias a su voluntad; y el bien universal no se encuentra sino en Dios (2003, pp. 89-90).

So pena de redundancia, resaltemos la forma en que estas palabras constatan que el único bien acabadamente universal se eleva necesariamente por encima del intelecto humano, es decir, que "el fin natural del hombre es insuficiente, o que apunta más allá de sí mismo” (Strauss, 2000, p. 219). Este fin último, único capaz de colmar el deseo de felicidad del hombre y conciliarlo con la verdadera virtud, ha de buscarse en la causa del fiat pronunciado en el momento de su creación, a saber: Dios. La constante deflación de los medios naturales que subyace al planteamiento teológico-político tomista tiene como correlato la idea de que cualquier posibilidad de virtud, perfección, felicidad y universalidad provienen de, y se despliegan hacia, el orden espiritual, desproveyendo de estas mismas insignias al orden temporal del reino, al que le quedan como única alternativa de fundamentación los elementos de la politicidad que remiten a la precariedad antropológica del ser humano. Recordemos que parte de las pretensiones conceptuales y contextuales en De regno consisten en asignar al orden civil de los reyes cierta autonomía de criterio respecto del orden espiritual del sacerdocio ${ }^{7}$; sin embargo, al efectuar la operación protosecularizadora de escisión entre el reino

7 El estudio sobre el despliegue y evolución de la disputa entre los dos modelos de soberanía del Medioevo (temporal-monárquico y espiritual-papal) encuentra una fuente autorizada en la obra de Bertelloni (2005), quien a propósito de la aproximación tomista al asunto señala que el Doctor Angélico "recoge el tema de la relación entre ambos poderes y [...] lo hace con cierta ingenuidad, pues procede como si esos dos poderes acordaran acerca de sus respectivas jurisdicciones, es decir, como si cada uno de ellos coincidiera perfectamente con el otro acerca de la jurisdicción que corresponde a cada uno de ambos soberanos" (p. 19). 
temporal y el reino de Dios, solo a uno de los dos le corresponde la cualidad de universalidad.

La primera consecuencia de este planteamiento no es otra que un nuevo desacuerdo frontal con la filosofía política de Aristóteles, consistente en esgrimir la idea de que la especie no está en condiciones de alcanzar la máxima perfección de su fin a través de ningún medio natural, de manera que, a nuestro juicio, Tomás parece acoger el naturalismo político aristotélico solo a condición de desvirtuar la dignidad del vínculo entre naturaleza humana y universalidad. Una segunda consecuencia, o deducción, es que el trastorno tomista de los conceptos aristotélicos viene dado por la dificultad que le supone a Tomás desplazar de su argumentación la insignia agustiniana, cuya más firme convicción, según lo advertimos, consiste en emplazar toda universalidad en el fuero divino propiciado por Dios.

\section{El reino desgarrado: entre la suficiencia de la vida y la fruición celestial}

Buena PARTE De las Cuestiones hasta acá planteadas acaban de cobrar sentido y encajar en el esquema conceptual tomista con la exposición de los fundamentos del reino, que es, después de todo, el propósito primordial del cual se ocupa el tratado y que vamos a considerar detenidamente a partir de aquí.

El proceso de fundación del reino se adelanta apropiando los recursos que la naturaleza dispone y haciendo de ellos, mediante su transformación por el trabajo de las manos, los artefactos necesarios para subsanar las deficiencias innatas de la especie. Tal procedimiento, según lo visto, se consuma en colaboración con las facultades sociales, intelectuales y corporales de muchos, pues no es posible para uno solo abastecerse por él mismo de lo necesario para la vida. Así, siguiendo el sentido de lo expresado hasta acá, y para responder a la cuestión que llevó a Tomás a redactar su tratado, el origen del reino, y por adhesión, el del naturalismo político tomista, está indefectiblemente anclado en las circunstancias de necesidad fisiológicas que acarrean por defecto una antropología herida a priori por la insuficiencia y la finitud. Que esta, y no otra, es la causa del reino se verifica, irónicamente, de acuerdo al método "aristoteleológico" del que Tomás es tributario; esto es, cuando se considera su fin propiamente intrínseco y aquello a lo cual se reduce la utilidad de la vida social, a saber: la paz que se sigue de la 
unidad de la multitud, o lo que es igual, la unidad de la paz, que no es otra cosa que la salud fisiológica del cuerpo político y que no implica nada distinto de esta suficiencia para la vida. Retornando a la metáfora náutica, el autor deja claro este punto al afirmar que:

en efecto, es propio del capitán llevar la nave, conservándola ilesa contra los peligros del mar, hasta el puerto de la salvación. Y el bien, la salud de la multitud asociada, consiste en que se conserve su unidad que se llama paz; removida la cual, perece la utilidad de la vida social (Tomás de Aquino, 2003, p. 68).

La manera en que se corrobora y complementa el planteamiento es mediante la proposición del tipo ideal de comunidades a las que, según Tomás, tendería una naturaleza social y política:

conviene que tanto sea más perfecta la sociedad de la multitud cuanto más suficiente sea por sí para lograr lo necesario para la vida. Se da cierta suficiencia de vida en una familia de una casa, a saber, lo que hace a los actos naturales de nutrición, generación de la prole y otros por el estilo; en un villorio, lo que compete al único oficio; y en la ciudad, que es la comunidad perfecta, lo que hace a todo lo necesario para la vida (Tomás de Aquino, 2003, p. 67).

Conforme a lo anterior, será más o menos perfecta la ciudad por cuanto corresponda en mayor o menor medida con la disposición acabada de lo necesario para la vida de sus miembros, propósito que, una vez conseguido, indicaría la consecución del máximo grado de perfección que un reino temporal está en condiciones de alcanzar. No obstante, al hacer de las disposiciones necesarias para la vida el criterio con arreglo al cual es posible evaluar el grado de perfección tanto de una casa o un villorrio como de una ciudad, Tomás hace estallar por los aires el criterio aristotélico de distinción entre la instancia política y sus variantes prepolíticas, aterrizando junto a "quienes creen que el político, el rey, el administrador de la casa y el amo se identifican [...], suponiendo que en nada se diferencia una casa grande de una ciudad-Estado pequeña” (Aristóteles, Política I, 1, 1252a). En este punto repara buena parte de la bibliografía crítica del texto para enseñar que una autoridad escolástica como Tomás "identifica la 'comunidad perfecta' (perfecta communitas) con la simple vida y la satisfacción de necesidades básicas” (Magoja, 2019, p. 345). Habermas (1987), por ejemplo, repara en el hecho de que "en Tomás de Aquino falta la distinción, tan decididamente expuesta por 
su filósofo [Aristóteles], entre el poder económico de disposición del señor de la casa y el poder político de dominio en la opinión pública" (p. 55). La lectura de Hannah Arendt (2003), por otra parte, es una de las más iluminadoras en este sentido, pues su hipótesis sobre "el profundo malentendido que expresa la traducción latina de 'político' como 'social'” reposa en buena medida en la equivalencia tomista entre el gobierno familiar y el gobierno político, proponiendo que el fin del reino no parece diferir más que formalmente del fin de una casa o una aldea (p. 41).

De este modo, nuevamente, se avizora una desproporción entre la polis aristotélica y el reino tomista, una que no se reduce a la extemporaneidad, pues mientras el reino consuma cabalmente su realización tras haber satisfecho aquello que es condicionante para la subsistencia de la multitud, propiciando en su interior la unidad de la paz, en la ciudad-Estado ideada en la Política la generación de la vida es condición necesaria pero no suficiente para considerar un orden civil enteramente realizado. En ese sentido, el naturalismo político anunciado por Tomás parece agotarse en conquistas que para Aristóteles devienen vinculadas a la naturaleza social y no a la naturaleza política, dado que "las relaciones [civiles] de dominio comienzan a ser despóticas y a asemejarse más a las relaciones [familiares] de dominio que tienen lugar en el oikos, y, con ello, a transformarse en relaciones económicas" (Bertelloni, 2005, p. 25). En otras palabras, en la recepción tomista de la filosofía política clásica se registra una suerte de inversión en la relación entre sociabilidad y politicidad, pues para Aristóteles el sentido de existencia de la primera es la realización de la anterioridad de la segunda, mientras en el texto de Tomás es la politicidad la que figura como medio para salvaguardar la unidad asociativa, lo cual confirma la tesis central habermasiana, a saber: "Tomás de Aquino transforma la política aristotélica en una filosofía de lo social” (Habermas, 1987, p. 56) ${ }^{8}$.

8 Un lustro antes de la publicación de Theorie und Praxis (1963) de Habermas, ya Hannah Arendt (1958) había hecho hincapié en que la "relación especial entre acción [política] y estar juntos parece justificar plenamente la primitiva traducción del zoon politikon aristotélico por animal socialis, que ya se encuentra en Séneca, y que luego se convirtió en la traducción modelo a través de Santo Tomás: homo est naturaliter politicus, id est, socialis ('el hombre es político por naturaleza, esto es, social')" (Arendt, 2003, p. 38). 
Allende lo referido, el teólogo italiano volverá sobre la cuestión de la virtud para acabar de calcular las dimensiones del reino, y alardeará un intento de rescatar cierto fin ulterior en función del cual la utilidad de la vida civil no estaría necesariamente circunscrita a la suficiencia de la vida; mas con este gesto, el Doctor Angélico acabará de desgarrar el sentido político del reino. Solo hacia el tercer capítulo del segundo libro, cuando da la impresión de que ya han sido enunciados los primeros principios en torno a los cuales se ordena un reino, su rey y sus súbditos, Tomás (2013) parece incurrir en un giro argumental que toma como punto de partida la siguiente consideración?:

conviene que sea el mismo el juicio respecto del fin de toda la multitud y el de un solo hombre. Entonces, si el fin último de un hombre fuera un bien cualquiera, que existiese en él mismo, y también lo fuera el fin último con el que se gobierna una multitud, sucedería que la multitud adquiriría tal bien y permanecería en él. Y si el fin último de un solo hombre o de la multitud fuera la vida corporal, o sea la salud del cuerpo, sería deber del médico conducir a ese fin (p. 113).

En efecto, entre aquellas cosas que se orientan de manera paralela hacia un fin intrínseco y uno extrínseco, figuran tanto el hombre como el reino. Ahora, suponiendo la ausencia del fin externo, el único propósito que les cabría a ambos sería su fin interno respectivo: la autoconservación o supervivencia, en el caso del hombre, y la suficiencia para la vida o unidad de la paz, para el caso del reino. No obstante -he aquí el desplazamiento por el cual se perseguiría una reconciliación con Aristóteles-, Tomás afirma que los hombres parecen agruparse no solamente para sobrevivir, sino que lo hacen específicamente para llevar una vida virtuosa o vivir bien. En palabras del propio autor, el aparente giro se consagra afirmando que "la vida virtuosa es el fin de la congregación humana" (Tomás de Aquino, 2003, pp. 113-114). Empero, luego de haber desarrollado, de la manera escrupulosa en que se hizo, toda una línea argumental que no tuvo la necesidad de apelar al sentido virtuoso de la política para expresar los aspectos esenciales

9 Dadas las peculiares condiciones de redacción de la obra, podríamos aventurarnos a especular una atribución de este giro a Tolomeo de Lucca, quien completó el De regno desde el punto en que lo habría abandonado Tomás. Sin embargo, como hemos indicado, lo que se diga respecto del lugar en que Tomás detuvo su pluma es necesariamente una conjetura incomprobable. 
que a ella subyacen, no resulta nada sencillo para Tomás recuperar aquello que ignoró metódicamente sin que se disparen las contradicciones entre los dos marcos conceptuales que moldean sus argumentos (Agustín y Aristóteles).

El tercer capítulo del segundo libro deviene, a nuestro entender, el momento crítico en De regno, pues es allí donde Tomás intenta conciliar la virtud política del reino con la divinidad celestial de Dios, labrando una composición en la que se admita, mediante la vida buena del orden temporal, algún sentido político-natural de virtud sin que la complacencia divina y sobrenatural quede comprometida como la más alta, perfecta y universal de las instancias posibles y deseables. Así pues, lo que afirma Tomás, no sin incurrir en múltiples salvedades, o "juegos de palabras" -según Bertelloni-, que dificultan el seguimiento ordenado de la composición argumentativa, es que "parece, en cambio, que el último fin de una multitud congregada es vivir según la virtud; en efecto, para esto se reúnen los hombres, para vivir bien todos juntos" (Tomás de Aquino, 2003, p. 113) ${ }^{10}$. No obstante, en las líneas sucesivas pone el mentís de esta idea advirtiendo lo siguiente:

Pero porque el hombre, al vivir según la virtud, se ordena a un fin ulterior que consiste en la fruición divina, como ya antes dijimos, y como conviene que el fin de la multitud humana no sea el mismo que el de un solo hombre, no es el fin último de una multitud congregada vivir según la virtud, sino por la vida virtuosa alcanzar la fruición divina. Entonces, si se pudiera alcanzar este fin por medio de la virtud de la naturaleza humana, sería necesario que el deber del rey le competiera dirigir a los hombres hacia este fin (2003, p. 114).

A renglón seguido, en la misma secuencia argumental, desdice nuevamente de su conjetura y concluye: "pero porque el fin de la fruición divina no lo consigue el hombre por la virtud humana, sino por la virtud divina, [...] llegar hasta aquel fin no es propio del régimen humano, sino del divino" (Tomás de Aquino, 2003, p. 114). Es esta la seña que clausura toda posibilidad de hacer de una vida virtuosa en el orden sublunar la causa final que fundamente el reino del que Tomás nos habla. Cuando el maestro de la Universidad de París afirma, desde las primeras

10 Compartimos el sentido de sospecha con el que Magoja (2019) evalúa este giro, reconociendo que "más allá de que aquí Tomás de Aquino introduce la realización de la virtud de los hombres como fin de la sociedad, no logra conciliar este elemento con las falencias que motivan el origen del regnum" (pp. 345-346). 
líneas del capítulo, que Dios es el único fin de todas las cosas, su aserción no constituye una mera forma de expresarse, sino que supone la constatación, a la que atiende con rigor su entramado teorético, de que "la virtud ocupa un lugar secundario en la argumentación” (Magoja, 2019, p. 346).

Del reino es posible decir que se instituye y se despliega con un propósito intrínseco de conservar ilesa la vida de sus miembros y un propósito extrínseco de prepararles - que no garantizarles- para la salvación divina. Así, en respuesta a la cuestión central sobre en quién recae la dignidad de dirigir a la multitud hacia la obtención de este, que es su fin último, exponemos lo siguiente: dado que dentro del reino yacen bifurcados los menesteres de su gobierno que competen a su proyección terrena, de un lado, y los que atañen a su designio espiritual, del otro, y considerando, además, que no hay rey sobre la tierra capaz de sostener la carga de Jesús, el Cristo -único al que le sería posible reconciliar ambos fines bajo la "simultaneidad de soberanías", referida por Bertelloni, de un mismo gobierno al que Tomás denomina "sacerdocio real"-, se concluye que la consecución del fin último del reino es una encomienda asignada al sacerdocio papal y no al rey:

el ministerio de tal reino, al estar separado lo espiritual de lo terreno, ha sido encomendado no a reyes terrenos, sino a los sacerdotes y, sobretodo, al sumo sacerdote, sucesor de Pedro, vicario de Cristo, el pontífice romano, a quien todos los reyes del pueblo cristiano conviene que estén sujetos como al mismo señor Jesucristo. [...] a ese a quien compete el cuidado del fin último se deben subordinar aquellos a los que atañe el cuidado de los fines anteriores y con su imperio ser dirigidos (Tomás de Aquino, 2003, p. 115).

La virtud del reino, reducida a la particularidad más escandalosa, se ve así sujeta a la paradoja de originarse de la radical finitud de la naturaleza humana y subordinarse ante la universal plenitud de un fin que le es impropio, y en eso consiste su desgarramiento, en que "el vivere secundum virtutem parece para Santo Tomás más importante como medio hacia la otra vida que como fin de la vida política” (Bertelloni, 2001, p. 62).

\section{Breves consideraciones finales}

ENSAYEMOS UN BREVE RECUENTO de los que, a nuestro juicio, serían los momentos más generales de la concatenación que la obra propone: como primer 
movimiento, Tomás apela a una naturaleza social y política emparentada con las precarias condiciones a las que se ve compelida la especie, las cuales deben ser enmendadas a través de la unidad de la paz en el reino; se justifica así la sociabilidad innata, pero se posterga la fundamentación de la politicidad en favor de la tematización del fin último que daría sentido al planteamiento; eventualmente, se introduce la salvedad de que la necesidad y la supervivencia no constituyen la única medida que explica la institución del reino, sino que, a través del acto asociativo y la organización civil, sería posible alcanzar un cierto grado de virtud. No obstante, en el tratamiento final del contenido virtuoso, se produce un inadvertido salto que va desde la aldea aristotélica hasta la Ciudad de Dios agustiniana, pues en la subordinación de toda cosecha natural a la fruición sobrenatural se diluye la promesa político-naturalista, y cuando conocimos el fin último, ya no estábamos hablando de cuestiones políticas a la manera de Aristóteles. Ciertamente, tanto en la observancia de lo intrínseco como en la contribución a lo extrínseco, lo que le compete al gobierno del rey -satisfacer lo necesario para la vida de la multitud congregada y conservar la unidad sobre la cual el sacerdocio encamina al reino hacia su encuentro con lo alto- es una cuestión prepolítica, observada en el rigor de Aristóteles, y apolítica, vista desde el ángulo de Agustín ${ }^{11}$. Para servirnos de una figura retórica que ilustre nuestra pauta interpretativa, lo que apreciamos es que Tomás inaugura su ensayo enseñando la forma en que Aristóteles desfila por la puerta principal de su esquema conceptual, adoptando las implicaciones protocolarias del naturalismo político, para luego sacarle por la ventana trasera arguyendo que aquello que en apariencia se nos presentaba como un fin no es otra cosa que un medio particular y circunscrito al verdadero fin universal.

De conformidad con lo anterior, deducimos que el Doctor Angélico no es un pensador que repita, actualice o profundice el naturalismo aristotélico en lo que respecta a su propia concepción de lo político. La apelación a la naturaleza política en ambos autores deviene con cadencias conceptuales distintas, presupuestos

11 La elocuencia y agudeza de Arendt vuelven a servirnos para reforzar la idea del distanciamiento que Tomás asume respecto de lo que Aristóteles entendía cuando reflexionaba acerca de la comunidad perfecta más allá de la mera asociación: "más que cualquier elaborada teoría, esta inconsciente sustitución de lo social por lo político revela hasta qué punto se había perdido el original concepto griego sobre la política" (Arendt, 2003, p. 38). 
diferentes y desembocaduras disímiles e incluso, en ocasiones, opuestas. Hay, en efecto, una recuperación del naturalismo aristotélico con vistas a explicar la política como una expresión de la naturaleza, no obstante, hay también una reconfiguración drástica de lo político, consistente en su "teologízación" -salvando las distancias con lo referido por Carl Schmitt en su Teología política (1922)por efecto del legado agustiniano. En este cruce, por un lado, se aturde -por no decir que se clausura- el vínculo entre política y universalidad y, por el otro, se auspicia el reclamo a la antropología de la necesidad para subsanar la deficiencia de fundamento para lo político ${ }^{12}$. Tomás deja así servida la matriz escolástica que alimentará las ideas de obras tan importantes como El defensor de la Paz (1324) de Marsilio de Padua, El Príncipe (1531) de Maquiavelo y el mismísimo Leviatán (1651) de Thomas Hobbes, quienes, entre otros, contribuirán al distintivo descreimiento moderno de las insinuaciones de la filosofía política clásica, y avanzarán en la prescripción de los primeros principios de la política moderna esgrimiendo una devaluada naturaleza antropológica, carente de toda virtud o universalidad, a la que solo le resta fundamentarse en la autoconservación fisiológica que reclama la realidad efectiva.

\section{Referencias}

Agustín de Hipona (2010). La Ciudad de Dios (trad. S. Santamarca del Río y M. Fuentes Lanero). Madrid: Editorial Tecnos.

Arendt, H. (2003). La condición humana (trad. R. Gil Novales). Buenos Aires: Paidós.

Aristóteles (1994). Metafisica (trad. T. Calvo Martínez). Madrid: Gredos.

Aristóteles (2015). Política (trad. G. Livov). Bernal: Universidad Nacional de Quilmes; Buenos Aires: Prometeo Libros.

12 De ahí que Habermas afirme que la filosofía social del De regno es el eslabón perdido entre la política de la virtud clásica y la política de la autocondervación moderna. Esto es, Tomás sería el vínculo que explica el contraste entre Aristóteles y Hobbes, pues "por una parte, [...] se sitúa completamente en la tradición aristotélica. [...] Pero, por otra parte, [...] ya no entiende esta comunidad de una forma genuinamente política: la civitas se ha convertido subrepticiamente en societas" (Habermas, 1987, p. 55). 
Bertelloni, F. (2001). El uso de la causalidad en la reflexión política de fines del siglo XIII y principios del XIv. En: A. Borón (ed.), Teoría y filosofía politica. La recuperación de los clásicos en el debate latinoamericano (pp. 56-78). Buenos Aires: Clacso.

Bertelloni, F. (2005). ¿El destino del Estado, coincide o no con el de sus dioses? Anales de Historia Antigua, Medieval y Moderna, 37(38), 107-133. doi: 10.34096/ahamm.v37.3513

Bertelloni, F. (2010). La teoría política medieval entre la tradición clásica y la modernidad. En: Roche Arnas, P. (coord.), El pensamiento politico en la Edad Media (pp. 17-40). Madrid: Fundación Ramón Arces.

Dotti, J. (1994). Pensamiento político moderno. En: E. de Olaso (ed.), Enciclopedia Iberoamericana de Filosofia, 6. Del renacimiento a la Ilustración I (pp. 53-76). Madrid: Trotta, Consejo Superior de Investigaciones Científicas. Habermas, J. (1987). Teoría y praxis: estudios de filosofía social (trad. de S. Mas Torres y C. Moya Espí). Madrid: Tecnos.

Magoja, E. (2019). La transformación conceptual del modelo político clásico del Estado en Tomás de Aquino. Díkaion, 28(2), 333-354. doi: 10.5294/ dika.2019.28.2.5.

Strauss, L. (2000). Derecho natural e historia (trad. Á Leiva Morales y R. Da Costa García). Barcelona: Círculo de Lectores.

Tomás de Aquino (2003). Del reino (trad. A. Tursi). Buenos Aires: Editorial Losada.

Tursi, A. (2003). Introducción y notas. En: Tomás de Aquino, Del reino (pp. 5158). Buenos Aires: Losada.

Ullman, W. (1985). Principios de gobierno y politica en la Edad Media (trad. de G. Sotiano). Madrid: Alianza Editorial. 